\title{
ERROR PROPAGATION FOR THREE COMMON HEIGHT-SYSTEM CORRECTIONS TO DIFFERENTIAL LEVELLING
}

M.S. Filmer

W.E. Featherstone

Mick Filmer (corresponding author)

Western Australian Centre for Geodesy \& The Institute for Geoscience Research,

Curtin University of Technology, GPO Box U1987, Perth, WA 6845, Australia

Telephone: +61-8-9266-2218

Fax: +61-8-9266-2703

Email: M.Filmer@curtin.edu.au

Will Featherstone

Western Australian Centre for Geodesy \& The Institute for Geoscience Research,

Curtin University of Technology, GPO Box U1987, Perth, WA 6845, Australia

Telephone: +61-8-9266-2734

Fax: +61-8-9266-2703

Email: W.Featherstone@curtin.edu.au 


\begin{abstract}
This paper investigates the propagation of input data errors through the application of Helmert orthometric, normal and normal-orthometric height corrections to differential levelling observations, these being the three principal height systems in practical use around the world. Height corrections are required to remove the systematic error resulting from the geometric non-parallelism of the Earth’s equipotential surfaces, but different height systems propagate errors differently. These systematic errors are thus present within levelling networks and subsequently in local vertical datums. Here, we show that the Helmert orthometric correction is sensitive to errors in the mean value of gravity along the plumbline, particularly for heights above $1000 \mathrm{~m}$. The normal correction is much less sensitive due to the use of normal gravity along the normal plumbline. The normal-orthometric correction of Rapp [1961] is largely insensitive to such errors, but it does not properly correct for the non-parallelism of the Earth's equipotential surfaces. Information showing the circumstances under which survey practitioners should apply height corrections to levelling lines is provided, demonstrating that normal-orthometric corrections only need be applied to class LC levelling lines that are to be used for large levelling networks extending in the north-south direction, particularly at high elevations.
\end{abstract}

Keywords: levelling, height systems, error analysis, Australia

\title{
INTRODUCTION
}

Height corrections (HCs) are applied to differential levelling observations to correct for the geometrical non-parallelism of the Earth's equipotential surfaces, thus attempting to achieve holonomity; i.e., to make the sum of error-free levelled height differences around a closed loop zero (cf. Sansò and Vaníček, 2006). Because gravity varies from place to place, the height determined from differential levelling depends on the route taken, meaning that an uncorrected loop will not close 
in theory. As such, a correction is required to achieve holonomity, as well as to determine heights that will correctly describe the flow of unrestricted fluids.

Figure 1 demonstrates how the levelled height difference ( $\Delta n$; dn in Figure 1) differs from the potential difference ( $\Delta W$; dW in Figure 1), the latter of which correctly determines the direction of unrestricted fluid flow. As physical height systems such as orthometric heights $\left(H^{O}\right)$ and normal heights $\left(H^{N}\right)$ are based on $\Delta W$ through geopotential numbers $(C)$, it follows that $\Delta n$ do not realise $H^{O}$ or $H^{N}$ correctly (cf. Meyer et al. 2006); nor do they realise normal-orthometric heights $\left(H^{N-O}\right)$, because the non-equipotential surfaces upon which they are based are also not parallel, generally converging towards the poles.

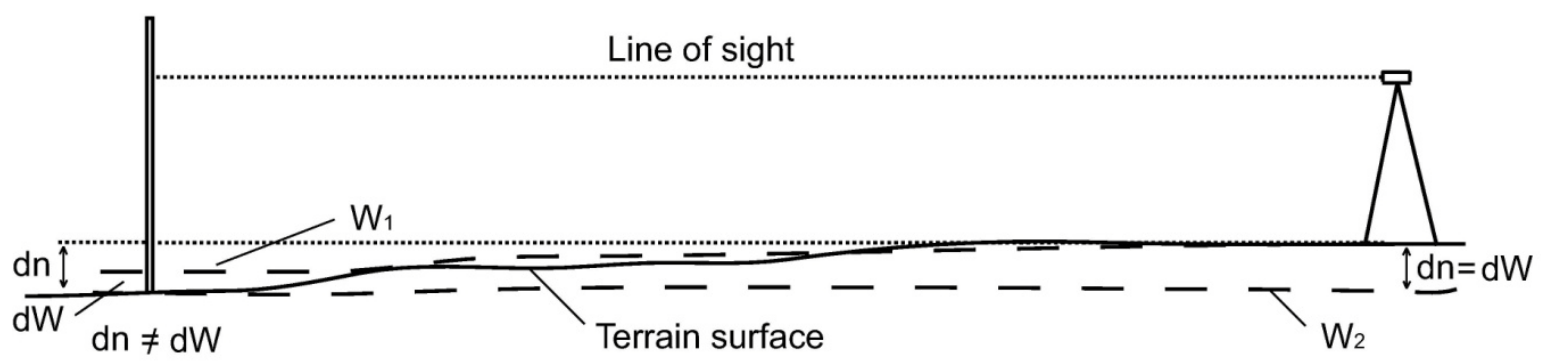

Figure 1. Non-parallelism of the equipotential surfaces $\mathrm{W}_{1}$ and $\mathrm{W}_{2}$, which leads to the non-holonomity of loop closures formed from accumulated levelled height differences $(d n)$. The observed dn is $d W\left(W_{1}-W_{2}\right)$ at the instrument, but at the staff, this is no longer the case. The difference between dn and dW at the staff (exaggerated here) is corrected by the application of HCs.

Figure 1 shows the line-of-sight to be tangengential to the equipotential surface $W_{1}$ at the levelling instrument. $\Delta n$ between the instrument and staff is $\Delta W$ at the instrument, but due to the non-parallelism of $W_{1}$ and $W_{2}, \Delta n \neq \Delta W$ at the staff. The magnitude $\Delta n-\Delta W$ at the staff (greatly exaggerated in Figure 1) is the systematic error that is corrected by the HC (usually over a sub-section containing a number of set-ups). $\Delta n-\Delta W$ is very small for each levelling setup, but accumulates incrementally over levelling sections, particularly in the north-south direction and in mountainous regions (e.g., Hwang and Hsiao, 2003). The accumulation of these differences is the reason why $\Sigma \Delta n$ 
around a closed levelling loop (running through different separations between equipotential surfaces) will not be zero. Sansò and Vaníček (2006) consider $H^{O}$ and $H^{N}$ to be holonomic, but $H^{N-O}$ cannot be considered so, although it can decrease the loop misclosure (cf. Filmer et al., 2010).

The HC applied depends on the height system in use, and can refer to the Earth's gravity field $\left(H^{O}\right)$, normal gravity generated by a reference ellipsoid $\left(H^{N-O}\right)$, or be a combination of both $\left(H^{N}\right)$. It is usual practice for national vertical datums to have HCs applied to their levelling network (cf. Marti and Schlatter 2002; Ihde et al. 2002). For example, normal-orthometric corrections (NOCs) were used in the Australian Height Datum (AHD; Roelse et al., 1971), Helmert orthometric corrections (HOCs) were used (indirectly) in the North American Vertical Datum (NAVD88; Zilkoski et al. 1992), while normal corrections $(N C \mathrm{~s})$ were used in the former USSR and many eastern European countries (Vaníček and Krakiwsky, 1982, p.371). However, it is uncommon for the appropriate HC to be applied by surveying practitioners when transferring 'official’ height values by differential levelling within these datums, despite recommendations to do so (e.g., ICSM, 2007, p.B-15).

Our initial research was conducted to identify the sensitivity of the Rapp (1961) normalorthometric correction $\left(N O C_{R}\right)$ to errors in the input values that could have propagated into the AHD (Roelse et al., 1971). However, we extended this study to the HOC and $N C$ to assist in gauging the suitability of these height systems for any new Australian vertical datum (cf. Allister and Featherstone, 2001; Filmer et al., 2010; Mitchell, 1973). There are numerous versions of the $H^{O}$ (e.g., Helmert 1890; Niethammer 1932; Mader 1954; Hwang and Hsaio 2003; Tenzer et al. 2005); we have chosen to investigate the Helmert version as this is the one commonly used, chiefly because it is easier to compute (see later).

Although brief sensitivity analyses have been conducted on a version of the $H^{O}$ (e.g., Strang van Hees, 1992; Rapp, 1961, p. 66-68; Vaníček et al., 1980), a more thorough analysis of HCs in use around the world and comparison of their susceptibility to input data errors is warranted. This paper thus identifies how errors in the input values for these three $\mathrm{HCs}\left(\mathrm{HOC}, N C\right.$ and $\left.N O C_{R}\right)$ can propagate into levelled height differences such that the magnitude of $\mathrm{HC}$ error is larger than the maximum 
allowable misclosure of the levelling section (see below). Importantly, here we are assessing the propagation of errors from the input parameters, not the effects of different approximations for computing mean gravity along the plumbline $(\bar{g})$, which are required by $H^{O}$.

The different sources of error that can contaminate HCs depend on the input values required in the formulas (defined later). Using the general law of error propagation (e.g., Lyons 1991), the sensitivity of the HC to errors in the different variables can be established. Here, input errors can be random, systematic or gross, although we acknowledge that the general case of error propagation is designed for random errors. This knowledge can be used to establish the accuracy to which the input values in the HC formulas must be known.

The three HCs assessed here have different advantages and disadvantages. $H^{O}$ requires assumptions on the variation of gravity within the topography, but best reflect the Earth's actual gravity field and are generally considered the most natural heights above sea level (e.g., Heiskanen and Moritz, 1967, p. 172), despite still not rigorously describing fluid flow (Jekeli 2000). $H^{N}$ does not require assumptions on the Earth's gravity within the topography, but refer to the telluroid, which is not an equipotential surface (see Figure 2) and does therefore not correctly reflect fluid flow. $H^{N-O}$ does not require gravity observations (both $H^{O}$ and $H^{N}$ require gravity values at benchmarks; BMs), but poorly represent the Earth’s true gravity field and thus fluid flow. In addition, Filmer et al. (2010) found that $H^{N-O}$ are not fully compatible with quasigeoid models as has previously been assumed (e.g., Featherstone and Kuhn, 2006; also see Featherstone et al., 2010).

\section{TEST DATA}

The data sets used for this study are the Australian National Levelling Network (ANLN), which was provided by Geoscience Australia (G. Johnston, 2007, pers. comm.) and the Earth Gravity Model 2008 (EGM2008; Pavlis et al., 2008) to degree 2160. Data from five levelling sections of the ANLN (see Filmer and Featherstone (2009) for a fuller analysis of the ANLN) were used as test sites 
(TSs) for the $H O C$ and $N C$ (Table 1). However, this is not a field test; it is a simulated error analysis using 'real' field data so that realistic gravity values can be used. The 'errors' resulting from this computation are simulated errors dependent on assumed errors in the input data.

Data shown in Table 1 are (cf. Table 3): observed height differences $(\Delta n)$ between BM1 and BM2 (start and end points of the levelling section), latitude of BM1 $\left(\phi_{1}\right), \operatorname{AHD} H^{N-O}$ at BM1 $\left(H_{1}\right)$ and BM2 $\left(H_{2}\right)$, and EGM2008-derived gravity at BM1 $\left(g_{1}\right)$ and BM2 $\left(g_{2}\right)$. TS5 is located on the highest point in Australia (Mt Kosciuszko; 36³0'S, 147¹5'E, $2228 \mathrm{~m}$ ).

\begin{tabular}{lcccccc}
\hline $\begin{array}{l}\text { Test } \\
\text { Section }\end{array}$ & $\begin{array}{c}\Delta n \\
(\mathrm{~m})\end{array}$ & $\begin{array}{c}\phi_{1} \\
(\text { south })\end{array}$ & $\begin{array}{c}\text { AHD } H_{1} \\
(\mathrm{~m})\end{array}$ & $\begin{array}{c}\text { AHD } H_{2} \\
(\mathrm{~m})\end{array}$ & $\begin{array}{c}\text { EGM2008 } g_{1} \\
(\text { Gals })\end{array}$ & $\begin{array}{c}\text { EGM2008 } g_{2} \\
(\text { Gals })\end{array}$ \\
\hline TS1 & 14.836 & $26^{\circ} 04^{\prime}$ & 505.686 & 520.523 & 978.860390 & 978.849108 \\
TS2 & 15.082 & $35^{\circ} 38^{\prime}$ & 1032.153 & 1047.230 & 979.553221 & 979.554246 \\
TS3 & 60.197 & $35^{\circ} 41^{\prime}$ & 1458.857 & 1519.056 & 979.437617 & 979.418736 \\
TS4 & 174.637 & $36^{\circ} 31^{\prime}$ & 1848.747 & 2023.388 & 979.433646 & 979.381902 \\
TS5 & 0.124 & $36^{\circ} 27^{\prime}$ & 2227.960 & 2228.084 & 979.303916 & 979.303875 \\
\hline
\end{tabular}

Table 1. Test data from ANLN and EGM2008 to degree 2160 for error propagation analysis of $H O C$ and $N C$.

EGM2008-derived gravity at BMs $\left(g_{B M}\right)$, is computed as $g_{B M}=\delta g_{B M}+\gamma_{B M}$ (cf. Heiskanen and Moritz, 1967, p.84), where $\delta g_{B M}$ is the gravity disturbance at the BM and $\gamma_{B M}$ is Geodetic Reference System 1980 (GRS80; Moritz, 1980) normal gravity at the BM. $\delta g_{B M}$ is computed as the spherical approximation of the radial component of the EGM2008 $\delta g$ using the FORTRAN77 program harmonic_synth.f (Holmes and Pavlis, 2008). $\gamma_{B M}$ requires normal gravity to be computed on the surface of the GRS80 ellipsoid $(\gamma)$, which is then continued upwards to the BM using the second-order free-air gravity correction (e.g., Hackney and Featherstone, 2006). For full details of this reconstruction technique, see Filmer et al. (2010).

The NOC uses constants from the normal gravity field generated by a normal ellipsoid of revolution (e.g., GRS80). Observed gravity values are not required at the BMs, as the $N O C$ is a function of BM latitude $\left(\phi_{B M}\right)$ and height $\left(H_{B M}\right)$ only. Three TSs for $N O C$ computations are in Table 
2: TS6 in the Australian Alps, TS7 in central Tasmania, while TS8 is a fictitious point near Australia’s southernmost point, with a height equivalent to Australia's highest point. The NOC is larger at locations with high elevations that are close to $45^{\circ}$ latitude (Rapp, 1961). GRS80 ellipsoid parameters are used for the NC and NOC and can be found in Moritz (1980); for this study, GRS80 values are assumed errorless.

\begin{tabular}{lcc}
\hline $\begin{array}{l}\text { Test } \\
\text { Section ID }\end{array}$ & $\begin{array}{c}\text { Mean } \\
\text { Latitude } \bar{\phi}\end{array}$ & $\begin{array}{c}\text { AHD } \bar{H} \\
(\mathrm{~m})\end{array}$ \\
\hline TS6 & $36^{\circ} 27^{\prime} \mathrm{S}$ & 2120.018 \\
TS7 & $41^{\circ} 44^{\prime} \mathrm{S}$ & 1180.820 \\
TS8 & $43^{\circ} 38^{\prime} \mathrm{S}$ & 2228.000 \\
\hline
\end{tabular}

Table 2. Test sections for the error propagation of the NOC. The NOC requires only average latitude $(\bar{\phi})$ and height $(\bar{H})$ of the levelling section.

\section{Discussion of errors in input data}

Input values required for the $H O C$ (Equation 3), $N C$ (Equation 12), and $N O C_{R}$ (Equation 26) are shown in Table 3. $H O C$ s are dependent only on $H_{B M}$ and $g_{B M}$, with the $N C$ additionally dependent on $\phi_{B M}$ and GRS80 parameters, which are required for the computation of normal gravity on the ellipsoid $(\gamma)$, and the integral mean of normal gravity along the normal plumbline $(\bar{\gamma})$. The NOC is dependent on $H_{B M}$, $\phi_{B M}$ and GRS80 parameters, but has no dependence on $g_{B M}$. All of these input values contain errors of some type that will propagate into the HC, depending on the sensitivity of the $\mathrm{HC}$ to each particular variable. A brief description of maximum errors for these input variables follows. 


\begin{tabular}{|c|l|c|c|c|}
\hline Input symbol & Input value description & HOC & $\boldsymbol{N C}$ & $\boldsymbol{N O C}_{\boldsymbol{R}}$ \\
\hline$\Delta n$ & Levelled height difference & Yes & Yes & Yes \\
\hline$H_{1}$ & Height at BM 1 & Yes & Yes & Yes \\
\hline$H_{2}$ & Height at BM 2 & Yes & Yes & Yes \\
\hline$g_{1}$ & Gravity at BM 1 & Yes & Yes & No \\
\hline$g_{2}$ & Gravity at BM 2 & Yes & Yes & No \\
\hline$\phi_{1}$ & Latitude at BM 1 & No & Yes & Yes \\
\hline$\phi_{2}$ & Latitude at BM 2 & No & Yes & Yes \\
\hline GRS80 & GRS80 parameters & No & Yes & Yes \\
\hline
\end{tabular}

Table 3. Input data requirements for the $H O C, N C$ and $N O C_{R}$.

Levelled height difference $(\Delta \boldsymbol{n})$. Differential levelling is an inherently precise system of measurement (Vaníček et al., 1980). Precision requirements are determined by closure tolerances for respective levelling order or class, which are usually determined by national geodetic agencies (e.g. for Australia, the Intergovernmental Committee on Surveying and Mapping, ICSM). In Australia, the required precision for levelling depends on the class of the survey. ICSM (2007, p.A-12) requires the misclose between forward and backward levelling runs to be $<r$, where $r=c \sqrt{d}$, and $r$ is the maximum allowable misclose (mm), $c$ is an empirically derived factor for each class of survey (see ICSM 2007, Table 4, p. A-13), and $d$ is the distance between two BMs (km), measured along the levelling route taken.

The ICSM (2007) levelling classes discussed here are class LA ( $c=4)$, class LB $(c=8)$, and class LC $(c=12)$. Thus, for a class LC levelling line that is $5 \mathrm{~km}$ long (a typical ANLN sub-section), the maximum allowable misclose is $26.8 \mathrm{~mm}$, which for this study is considered an upper bound for random errors in $\Delta n$. However, a levelling misclose can comprise small systematic errors and blunders, or larger errors that may cancel out and thus remain undetected. As levelling is poorly conditioned, it is also possible for large compensating blunders (of similar magnitude, but opposite signs) to remain hidden in a within-tolerance levelling line (e.g., Holloway 1988). Although acknowledging that random and systematic levelling errors are usually small $(\Delta n<30 \mathrm{~mm}$, where $d=$ 
$5 \mathrm{~km})$, we will also consider the effects of gross errors up to $1 \mathrm{~m}(\Delta n=1 \mathrm{~m})$, as errors of this magnitude still reside in the ANLN (Filmer and Featherstone ,2009).

BM height $\left(\boldsymbol{H}_{\boldsymbol{B} M}\right)$. The accuracy of $H_{B M}$ with respect to the local height datum is dependent on the propagation of systematic and gross levelling errors through the levelling network. The distortion of vertical datums fixed to MSL (e.g., AHD) due to sea surface topography (SSTop), further complicates the accuracy of $H_{B M}$, given that the integrity of the particular height system is corrupted by using MSL constraints in the adjustment. If we allow $1 \mathrm{~m}$ for the effects of gross and systematic levelling errors in the datum (e.g., Filmer and Featherstone, 2009) and also $1 \mathrm{~m}$ for the effect of network distortion due to using SSTop contaminated MSL constraints (cf. Featherstone et al., 2010), we crudely estimate a maximum error of $\sim 2 \mathrm{~m}$ in the value of $H_{B M}$.

However, a surveyor may not have access to an official $H_{B M}$ with respect to the local vertical datum in some cases. Because the levelling line may not be connected to datum, a crude estimate of the start and end points of the level line will have to be made. Here, the potential for a large error in $H_{B M}$ is present, so $H_{B M}$ errors up to $10 \mathrm{~m}$ will be tested. Note also that although $H^{O}$ should be used for the $H O C$ ( $H_{1}$ and $H_{2}$ in Equation (3)), and $H^{N}$ for the $N C$ (Equation 12), here we use ANLN $H^{N-O}$ in the HOC and $N C$, as it is the only height available. Filmer et al. (2010) found differences between $H^{O}$ and $H^{N-O}$ can reach $440 \mathrm{~mm}$ in Australia (STD $\pm 26 \mathrm{~mm}$ ), while maximum differences between $H^{N}$ and $H^{N-O}$ are $170 \mathrm{~mm}(\mathrm{STD} \pm 17 \mathrm{~mm})$. These differences are subsumed within the $\sim 2$ m $H_{B M}$ error suggested above.

BM Gravity $\left(\boldsymbol{g}_{\boldsymbol{B} \boldsymbol{M}}\right)$. Errors in $g_{B M}$ may come from a number of different sources and depends on how $g_{B M}$ is realised. Directly observed $g_{B M}$ using modern gravimeters will usually be of high accuracy (1-15 $\mu \mathrm{ms}^{-2}$; Murray, 1997). If there is no directly observed $g_{B M}$ (as is often the case for levelling networks), then surrounding $g_{B M}$ can be estimated by interpolation from surrounding 
gravity observations, or from modelled gravity (e.g., EGM2008). Here, we use EGM2008 $g_{B M}$, which although an effective substitute for directly observed or interpolated $g_{B M}$, can also contain numerous error sources. These include difficulties modelling the variable gravity field in mountainous regions, and omission error, where high-frequency gravity field information at wavelengths $<5$ arc-minutes ( $~ 9 \mathrm{~km}$ ), which is the spatial resolution of EGM2008, is excluded from the modelled gravity field (e.g., Claessens et al., 2009).

This paper does not consider the discretisation error associated with the discrete summation rather than an integral of surface gravity $g$ (see Papp et al., 2009), or sampling density of gravity observations (see Torge, 2001; Hirt and Flury, 2008; Papp et al., 2009). These issues are of a more conceptual nature, with the effect on the HC generally small. EGM2008 $g_{B M}$ errors (compared to directly observed $g_{B M}$ ) have been shown to be as large as $50-60 \mathrm{mGal}$ in areas of high elevation and rugged terrain (Filmer et al., 2010), and it is the effect of errors of this type on gravimetric HC that are investigated in this paper. A maximum error in $g_{B M}$ in mountainous terrain of up to $100 \mathrm{mGal}$ is considered here.

BM Latitude $\left(\boldsymbol{\phi}_{\boldsymbol{B} M}\right) . \phi_{B M}$ is required for the $N O C_{R}$ (Equations 26-36) and $N C$ (Equations 12-15). ANLN $\phi_{B M}$ have an accuracy of \pm 30 arc-seconds and sometimes worse, as the BM positions were scaled from 1:250,000 maps to the nearest arc-minute (Roelse et al., 1971, p. 40), although some have since been updated by State and Territory geodetic agencies (G. Holloway, 2009, pers. comm.). GNSS allows $\phi_{B M}$ to be accurately located (several metres is sufficient for HCs), suggesting that GNSS receivers should be included in a levelling party's equipment list, despite adding to the survey expense by having to observe BM positions. However, for practitioners that do not have GNSS receivers, or access to accurate BM positions, errors of \pm 30 arc-seconds for AHD $\phi_{B M}$ are likely, or conceivably \pm 2 arc-minutes where there is no AHD $\phi_{B M}$ and a crude estimate in the field is required. 


\section{HELMERT ORTHOMETRIC HEIGHTS}

Helmert $H^{O}$, like all physical height systems, are based on the geopotential number $C$, $\left(C=W_{P}-\right.$ $W_{0}$ ) which is the difference between gravity potential at point $P\left(W_{P}\right)$ on the topographic surface and gravity potential on the geoid ( $W_{0}$; see Figure 2). Helmert $H^{O}$ is conceptually simple and easy to compute compared to the other versions of $H^{O}$ listed earlier, and is defined as (e.g., Heiskanen and Moritz, 1967, p.166)

$H^{O}=\frac{C}{\bar{g}}$

where $\bar{g}$ is the integral mean value of gravity along the curved and torsioned plumbline between

point $P$ on the topographic surface and $P_{0}$ on the geoid (Figure 2). The difference between Helmert $H^{O}$ and other versions of $H^{O}$ is the method used to compute $\bar{g}$, as the plumbline is inside the topography, so $\bar{g}$ can only ever be approximated (cf. Strange, 1982). The approximation of $\bar{g}$ contributes to the inability of $H^{O}$ to fully determine the direction of fluid flow.

\section{Poincaré-Prey gravity reduction}

The simple Poincaré-Prey (SPP) reduction is used to approximate $\bar{g}$ (at BM $1 ; \bar{g}_{1}$; at BM $2 ; \bar{g}_{2}$ ) for the Helmert $H^{O}$ and is (Heiskanen and Moritz, 1967, p.164)

$$
g_{Q^{o}}=g_{B M}+0.0848\left(H_{P}-H_{Q^{o}}\right)
$$

where $g_{Q^{o}}$ is the value of gravity (Gals) at the midpoint along the plumbline $P-P_{0}\left(Q^{O}\right.$, see Figure 2), $g_{P}$ (Gals) is the value of observed gravity at $P, H_{P}^{O}(\mathrm{~km})$ is the Helmert $H^{O}$ of $P$ and $H_{Q^{O}}(\mathrm{~km})$ is the Helmert $H^{O}$ of $Q^{O}$. Vertical datums that employ $H^{O}$ (e.g., NAVD88; Zilkoski 1992) usually use Helmert $H^{O}$ due to the ease of computation compared to more rigorous versions of $H^{O}$. However, the SPP makes several approximations, including the neglect of terrain effects and variations in the Earth’s topographic mass-density. 


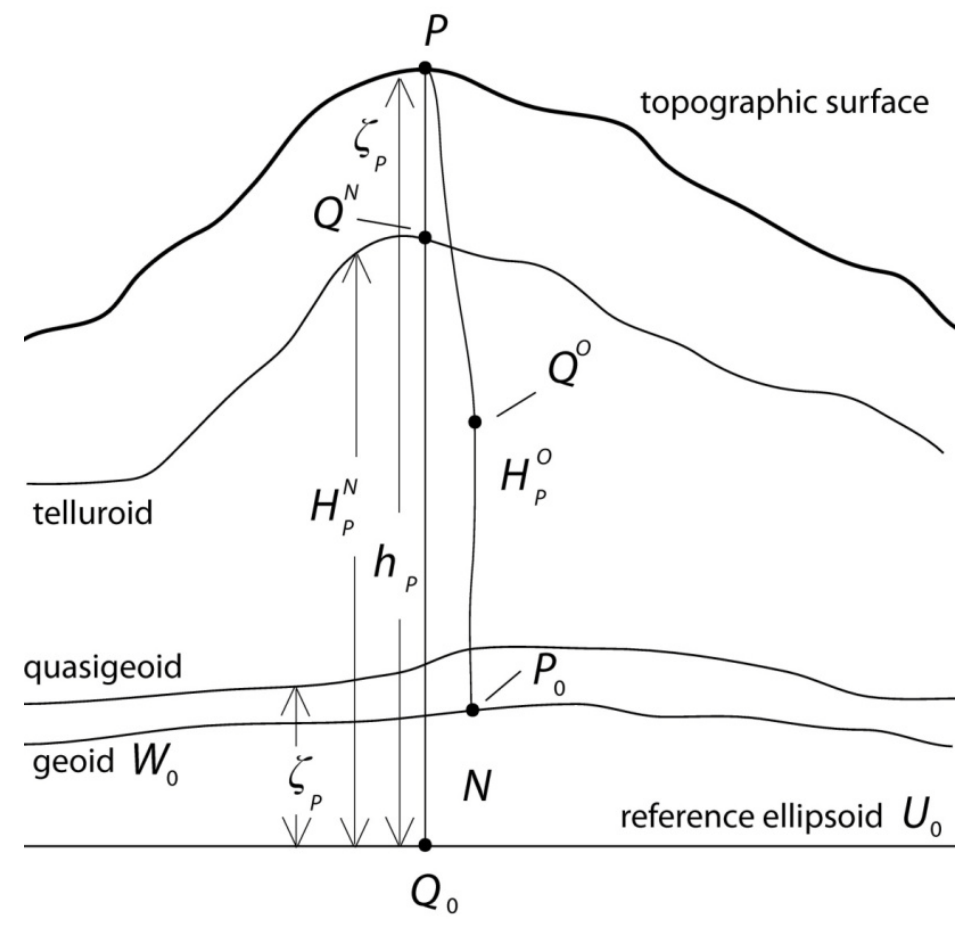

Figure 2. Shows normal heights $\left(H_{P}^{N}\right.$; relating to the telluroid) and Helmert orthometric heights $H_{P}^{O}$ (relating to the geoid) of point $P . H_{P}^{N}$ are measured along the (slightly curved) normal plumbline $Q^{N}-Q_{0}$, while $H_{P}^{O}$ are measured along the (curved and torsioned) actual plumbline $P-P_{0}$. The ellipsoid height of $P$ is $h_{P}$ and is the linear distance (along the straight ellipsoidal normal) of $P$ above the reference ellipsoid.

\section{The Helmert orthometric correction}

In most practical applications, $H O C$ s are usually applied to $\Delta n$, although the geopotential number method (e.g., Marti and Schlatter 2002; Ihde et al. 2002) is also used. There are numerous different HOCs available, but here we will investigate the commonly used version of the $\mathrm{HOC}$ found in Heiskanen and Moritz (1967, p.168)

$H O C=\sum_{1}^{2} \frac{g-\gamma_{0}}{\gamma_{0}} \Delta n+\frac{\bar{g}_{1}-\gamma_{0}}{\gamma_{0}} H_{1}-\frac{\bar{g}_{2}-\gamma_{0}}{\gamma_{0}} H_{2}$

In Equation (3), $g$ is the simple mean value of surface gravity between BM1 and BM2 at each end of the levelling section, $\gamma_{0}$ is a constant value of normal gravity at the ellipsoid (usually at $45^{\circ}$ latitude), 
$\bar{g}_{1}$ and $\bar{g}_{2}$ are the integral mean values of gravity along the plumblines that pass through BM1 and BM2 respectively, and $H_{1}$ and $H_{2}$ are the heights of these BMs.

\section{Partial derivatives of HOC}

With this type of analysis (e.g., Lyons 1991), the partial derivative of the HOC with respect to each variable is taken. From Equation (3), the total differential is

$\delta H O C=\frac{\partial H O C}{\partial g} \delta g+\frac{\partial H O C}{\partial \Delta n} \delta \Delta n+\frac{\partial H O C}{\partial \bar{g}_{1}} \delta \bar{g}_{1}+\frac{\partial H O C}{\partial \bar{g}_{2}} \delta \bar{g}_{2}+\frac{\partial H O C}{\partial H_{1}} \delta H_{1}+\frac{\partial H O C}{\partial H_{2}} \delta H_{2}$

with the partial derivatives (cf. Vaníček et al., 1980, p.516)

$\frac{\partial H O C}{\partial g}=\frac{\Delta n}{\gamma_{0}}$

$\frac{\partial H O C}{\partial \Delta n}=\frac{g-\gamma_{0}}{\gamma_{0}}$

$\frac{\partial H O C}{\partial \bar{g}_{1}}=\frac{H_{1}}{\gamma_{0}}$

$\frac{\partial H O C}{\partial \bar{g}_{2}}=-\frac{H_{2}}{\gamma_{0}}$

$\frac{\partial H O C}{\partial H_{1}}=\frac{\bar{g}_{1}-\gamma_{0}}{\gamma_{0}}$

$\frac{\partial H O C}{\partial H_{2}}=-\frac{\bar{g}_{2}-\gamma_{0}}{\gamma_{0}}$

$\gamma_{0}$ is taken as an error-free constant, so is not tested here.

The levelling and gravity information in Table 1 was used in Equations (5-10) to evaluate the partial derivatives, which were then substituted into the relevant term for Equation (4) so that the effect of each input value on $H O C$ error $(\delta H O C)$ could be assessed. 


\section{Results for $\mathrm{HOC}$}

HOC sensitivity to $\Delta \boldsymbol{n}$ errors $(\boldsymbol{\delta} \boldsymbol{\Delta} \boldsymbol{n}) . \delta H O C$ due to $\delta \Delta n$ is $\pm 2 \mathrm{~mm}$ at TS1, and $\pm 1 \mathrm{~mm}$ for TS2-TS5 when $\delta \Delta n$ is assumed to be $\pm 1 \mathrm{~m}$, indicating latitude dependence (Equation 6; cf. Equations 9 and 10). However, for ICSM (2007) class LC maximum allowable misclose, where $\delta \Delta n$ is \pm 26.8 mm over a $5 \mathrm{~km}$ levelling section, the $\delta H O C$ caused by $\delta \Delta n$ is $< \pm 1 \mathrm{~mm}$ for all TSs. Under most circumstances, therefore, $\delta \Delta n$ will not significantly contribute to $\delta H O C$.

HOC sensitivity to $\boldsymbol{g}$ errors $(\boldsymbol{\delta} \boldsymbol{g})$. The effect of $\delta g$ (not to be confused with the gravity disturbance) on $\delta H O C$ (Figure 3) is proportional to $\Delta n$ (Equation 5). Thus, $\delta g$ will have a larger effect on $\delta H O C$ when $\triangle n$ is large. This is demonstrated in Figure 3, where $\delta H O C$ is largest at TS4 ( $\Delta n$ is $174.637 \mathrm{~m}$ ), reaching $\pm 18 \mathrm{~mm}$ when $\delta g$ is $\pm 100 \mathrm{mGal}$. This can be compared with $\delta H O C$ for TS5 ( $\Delta n$ is $0.124 \mathrm{~m}$ ), which is negligible. However, the $H O C$ is not particularly sensitive to $\delta g$, as a $\pm 100 \mathrm{mGal}$ error, over a section where $\Delta n$ is $100 \mathrm{~m}$, would only propagate a $\sim \pm 10 \mathrm{~mm}$ error into the $H O C$, though it is acknowledged that for high precision levelling, this may become significant.

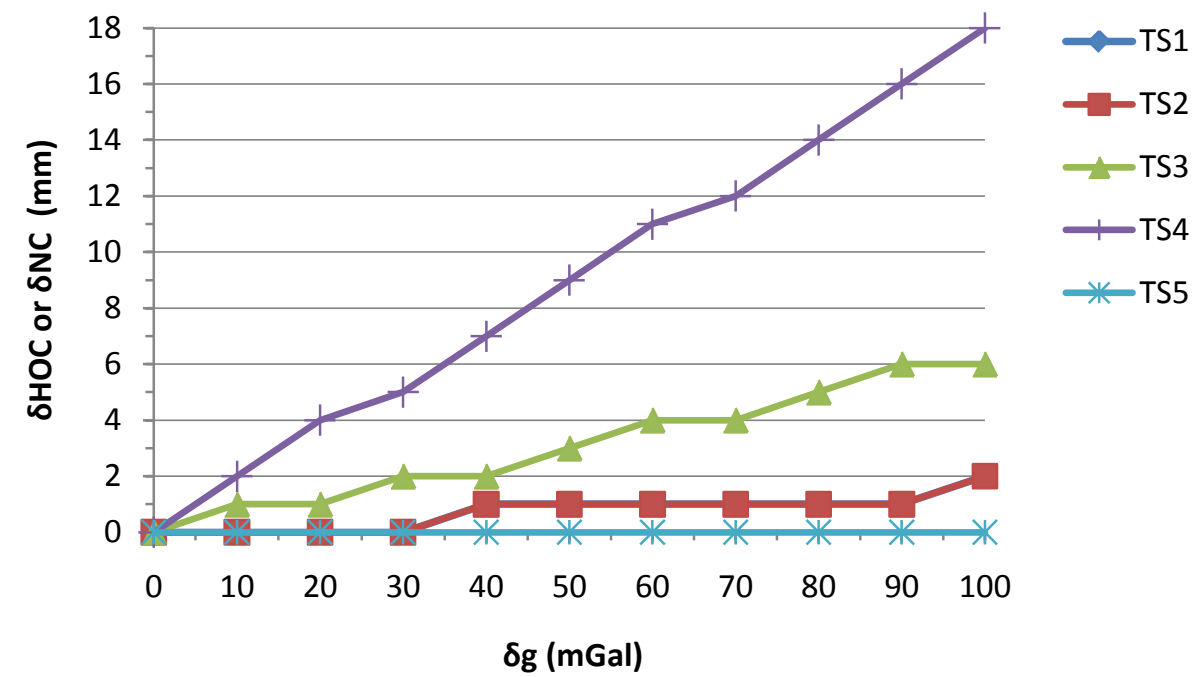

Figure 3. $\delta H O C$ caused by $\delta g$ (mGal). Note that $\delta H O C$ for TS1 is the same as for TS2. 
$\boldsymbol{H O C}$ sensitivity to $\overline{\boldsymbol{g}}$ errors $(\boldsymbol{\delta} \overline{\boldsymbol{g}})$. Here, we evaluate $\delta H O C$ due to $\delta \bar{g}_{1}$ (Equation 7 ) only, as Equation (8) yields the same result (if we ignore $H_{1} \neq H_{2}$ ), but with opposite signs. Equation (7) also shows that the effect of $\delta \bar{g}$ on $\delta H O C$ is proportional to $H_{B M}$. Figure 4 indicates that $\delta H O C$ is largest for TS5 ( $H_{1}$ is 2227.960$), ~ \pm 230 \mathrm{~mm}$ when $\delta \bar{g}$ is $\pm 100 \mathrm{mGal}$ (cf. Heiskanen and Moritz (1967, p.169), who estimate $\delta H O C$ is $\pm 100 \mathrm{~mm}$ when $\delta \bar{g}$ is $\pm 100 \mathrm{mGal}$ and $H_{B M}$ is $1000 \mathrm{~m}$ ). However, this error does not accumulate, as $\delta \bar{g}_{1}$ only affects Helmert $H^{O}$ at BM 1 . Thus, $\delta H O C$ is rather sensitive to $\delta \bar{g}$, with the potential to cause significant errors in Helmert $H^{O}$ at BMs where there are large errors in $g_{B M}$.

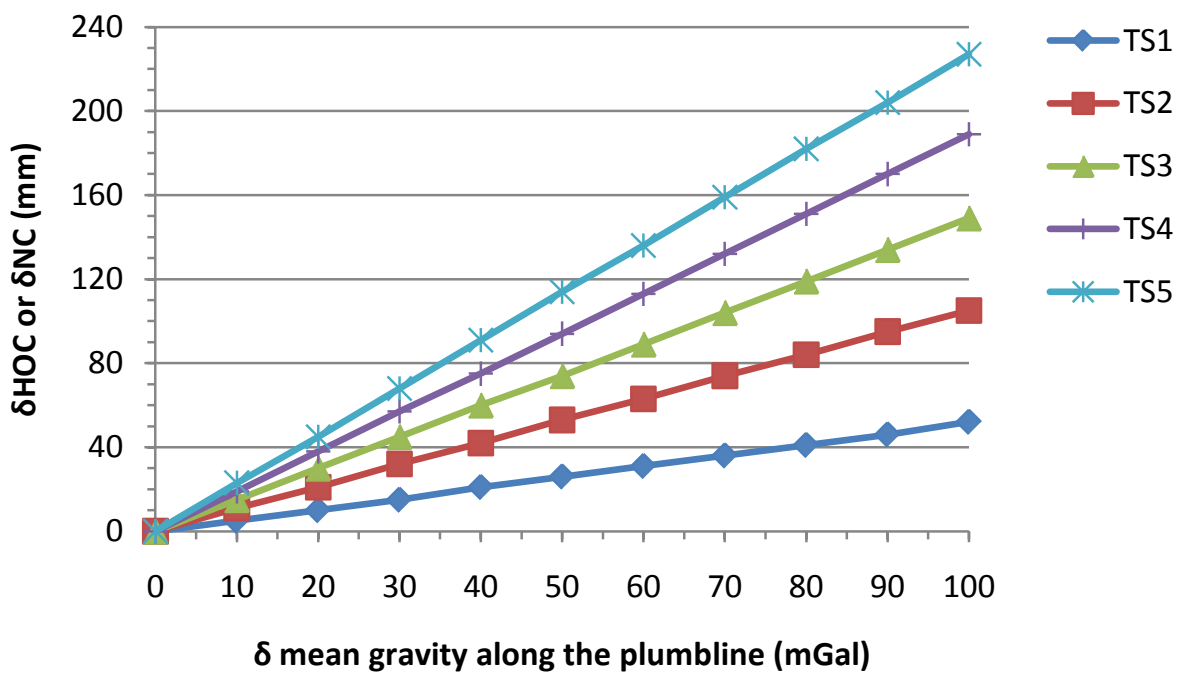

Figure 4. $\delta H O C$ caused by $\delta \bar{g}$ (mGal).

$\boldsymbol{H} O \boldsymbol{C}$ sensitivity to $\boldsymbol{H}_{\boldsymbol{B M}}$ errors $\left(\boldsymbol{\delta} \boldsymbol{H}_{\boldsymbol{B M}}\right)$. As for $\delta \bar{g}$, $\delta H O C$ resulting from $\delta H_{B M}$ are computed using just $\delta H_{1}$ (Equation 9), which indicates that $\delta H O C$ resulting from $\delta H_{1}$ is a function of $\bar{g}_{1}$ and the assumed-errorless $\gamma_{0}$. Since both $H_{B M}$ and $\phi_{B M}$ have an influence on the value of $\bar{g}_{B M}$, the height and location of the BM will affect $\delta H O C$ resulting from $\delta H_{B M}$. Figure 5 shows that the magnitude of $\delta H O C$ (TS1) is $\pm 18 \mathrm{~mm}$ when $\delta H_{B M}$ is $\pm 10 \mathrm{~m}$. The similar magnitude of $\delta H O C$ for TS2-TS5 (similar $\phi_{B M}$; see Table 1) compared to $\delta H O C$ for TS1 ( 10 further north) indicates that the effect of $\delta H_{B M}$ is mostly latitude-dependent. However, maximum $\delta H^{O}$ is likely to be $< \pm 2 \mathrm{~m}$, so 
that the magnitude of $\delta H O C$ resulting from $\delta H_{B M}$ is $< \pm 4 \mathrm{~mm}$ (Figure 5), suggesting that $\delta H_{B M}<$ $\pm 2 \mathrm{~m}$ does not cause a significant $\delta H O C$.

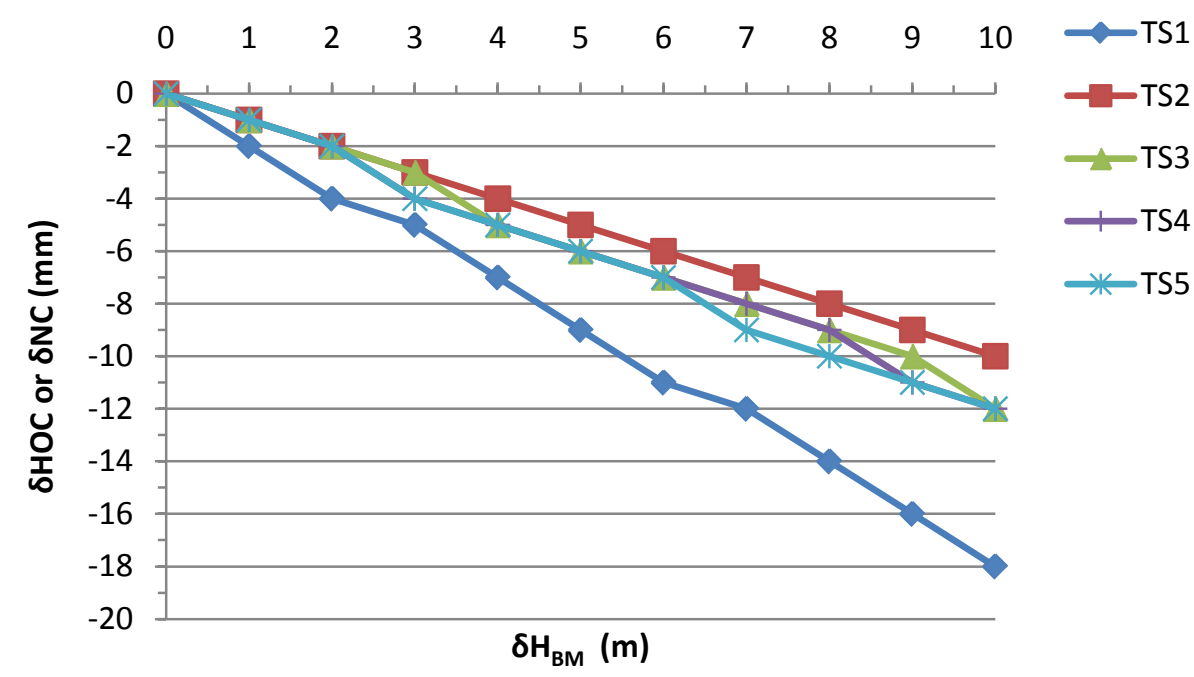

Figure 5. $\delta H O C$ resulting from $\delta H_{B M}$.

\section{MOLODENSKY NORMAL HEIGHTS}

$H^{N}$ was introduced by Molodensky in 1945 (Molodensky et al., 1962, loc. cit.). This height system replaces $\bar{g}$ (Equation 1 ) by the integral mean of normal gravity along the normal plumbline $(\bar{\gamma})$ between the ellipsoid and the telluroid, giving (Heiskanen and Moritz, 1967, p.171)

$H^{N}=\frac{C}{\bar{\gamma}}$

The telluroid is defined as the point on the normal plumbline $\left(Q^{N}\right)$ where normal potential $U_{Q}$ is equal to the actual Earth's potential at $P\left(W_{P}\right.$; see Figure 2$) . H_{P}^{N}$ is the distance along the slightly curved normal plumbline between $Q_{N}$ on the telluroid and $Q_{0}$ on the ellipsoid. Although the height anomaly $\left(\zeta_{P}\right)$ is defined between the telluroid and the topographic surface, $\left(\zeta_{P}\right)$ can be plotted above the reference ellipsoid to map the quasigeoid (Figure 2). However, the quasigeoid is not an equipotential 
surface in either the normal or actual gravity field (Jekeli, 2000, p.11), so has lesser physical meaning. Thus, for practical purposes, $H_{P}^{N}$ is the normal height of $P$ above the quasigeoid, in analogy with $H_{P}^{O}$.

\section{Normal height correction}

Like $H^{O}, H^{N}$ are usually computed as corrections (cf. Marti and Schlatter, 2002; Ihde et al., 2002) to $\Delta n$ (Heiskanen and Moritz, 1967, p.171)

$N C=\sum_{1}^{2} \frac{g-\gamma_{0}}{\gamma_{0}} \Delta n+\frac{\bar{\gamma}_{1}-\gamma_{0}}{\gamma_{0}} H_{1}-\frac{\bar{\gamma}_{2}-\gamma_{0}}{\gamma_{0}} H_{2}$

where $\bar{\gamma}_{1}$ and $\bar{\gamma}_{2}$ are the integral mean of normal gravity along the normal plumbline at BM1 and BM2 respectively. Apart from the use of $H^{N}$ rather than $H^{O}$ in the $N C$ (AHD $H^{N-O}$ substituted for both in this study) the use of $\bar{\gamma}$ instead of $\bar{g}$ is the only difference between Equations (12) and (3). However, it is quite critical as it avoids the assumptions required for $\bar{g}$ regarding the topographic masses (see earlier discussion). By contrast, $\bar{\gamma}$ can be computed analytically (Heiskanen and Moritz, 1967, p.170)

$\bar{\gamma}=\gamma\left[1-\left(1+f+m-2 f \sin ^{2} \phi_{B M}\right) \frac{H^{N}}{a}+\left(\frac{H^{N}}{a}\right)^{2}\right]$

where $f$ is the geometrical flattening of the ellipsoid, $m$ is the geodetic parameter (ratio of gravitational and centrifugal forces at the equator), and $a$ is the length of the semi-major axis. $\gamma$ is the value of normal gravity on the surface of the GRS80 ellipsoid at $\phi_{B M}$ and is computed using the form (e.g., Moritz 1980)

$\gamma=\gamma_{e} \frac{1+k \sin ^{2} \phi_{B M}}{\sqrt{1+e^{2} \sin ^{2} \phi_{B M}}}$

where $\gamma_{e}$ is normal gravity at the equator, $e^{2}$ is the square of the first eccentricity of the ellipsoid, and $k$ is (Moritz 1980) 
$k=\frac{b \gamma_{p}}{a \gamma_{e}}$

where $b$ is the length of the semi-minor axis of the ellipsoid and $\gamma_{p}$ is normal gravity at the pole.

However, despite being analytical, $\bar{\gamma}$ is subject to input data errors in $\phi_{B M}\left(\delta \phi_{B M}\right)$ and $H^{N}\left(\delta H^{N}\right)$.

See later for the treatment of these errors.

\section{Partial derivatives of NC}

In analogy with the $H O C$, the total differential of the $N C$ is

$\delta N C=\frac{\partial N C}{\partial g} \delta g+\frac{\partial N C}{\partial \Delta n} \delta \Delta n+\frac{\partial N C}{\partial \bar{\gamma}_{1}} \delta \bar{\gamma}_{1}+\frac{\partial N C}{\partial \bar{\gamma}_{2}} \delta \bar{\gamma}_{2}+\frac{\partial N C}{\partial H_{1}} \delta H_{1}+\frac{\partial N C}{\partial H_{2}} \delta H_{2}$

and the partial derivatives are

$\frac{\partial N C}{\partial g}=\frac{\Delta n}{\gamma_{0}}$

$\frac{\partial N C}{\partial \Delta n}=\frac{g-\gamma_{0}}{\gamma_{0}}$

$\frac{\partial N C}{\partial \bar{\gamma}_{1}}=\frac{H_{1}}{\gamma_{0}}$

$\frac{\partial N C}{\partial \bar{\gamma}_{2}}=-\frac{H_{2}}{\gamma_{0}}$

$\frac{\partial N C}{\partial H_{1}}=\frac{\bar{\gamma}_{1}-\gamma_{0}}{\gamma_{0}}$

$\frac{\partial N C}{\partial H_{2}}=-\frac{\bar{\gamma}_{2}-\gamma_{0}}{\gamma_{0}}$

As with the $H O C$, information from Table 1 was used in Equations (17) - (22) and then substituted into Equation (16) to determine $\delta N C$ with respect to errors in the different input variables. 


\section{Results for NC}

Equations (17) and (18) for the $N C$ are essentially the same as Equations (5) and (6) for the HOC. Therefore, like $\delta H O C$, the magnitude of $\delta N C$ is $< \pm 20 \mathrm{~mm}$ provided $\delta g$ is $< \pm 100 \mathrm{mGal}$ (TS4), and $<$ $\pm 2 \mathrm{~mm}$ when $\delta \Delta n$ is $< \pm 1 \mathrm{~m}$. The effects of the remaining variables on $\delta N C$ are described below.

$\bar{\gamma}$ sensitivity to $\delta \phi_{B M}$ and $\delta \boldsymbol{H}^{N}$. Here, the effect of $\delta \phi_{B M}$ and $\delta H^{N}$ on $\delta \bar{\gamma}$ are investigated. The partial derivative of $\bar{\gamma}$ with respect to $H^{N}$ is

$\frac{\partial \bar{\gamma}}{\partial H^{N}}=-\frac{\gamma}{a}\left[1+f+m-2 f \sin ^{2} \phi_{B M}-\frac{2 H^{N}}{a}\right]$,

so that $\delta \bar{\gamma}$ caused by $\delta H^{N}$ is then

$\delta \bar{\gamma}=\frac{\partial \bar{\gamma}}{\partial H^{N}} \delta H^{N}$,

with $\delta \bar{\gamma}$ computed for all TSs (Table 1). $\delta \bar{\gamma}$ increases linearly as $\delta H^{N}$ increases, at $0.1542-0.1543$ mGal $\mathrm{m}^{-1}$, with the slightly lesser rate at higher elevations (TS3, TS4, TS5), which is approximately half the linear vertical gradient of normal gravity in free air $\left(0.3086 \mathrm{mGal} \mathrm{m}^{-1}\right)$.

$\delta \bar{\gamma}$ caused by $\delta \phi_{B M}$ is more complex than the effects of $\delta H^{N}$, because $\bar{\gamma}$ is dependent on $\gamma$ (Equation 13), which itself is dependent on $\phi_{B M}$ (Equation 14). Instead of using the general law of error propagation to assess the sensitivity of $\bar{\gamma}$ to $\delta \phi_{B M}$, a numerical simulation is used to evaluate $\delta \bar{\gamma}$ caused by $\delta \phi_{B M}$. Table 4 shows that when $\delta \phi_{B M}$ is \pm 1 arc-minute, $\delta \bar{\gamma}$ is between $\pm 1.187 \mathrm{mGal}$ at TS1, and $\pm 1.441 \mathrm{mGal}$ at TS4, using Equations (13) and (14). This is compared to an error in $\gamma(\delta \gamma$; $\delta \phi_{B M}$ also \pm 1 arc-minute) using Equation (14), of $\pm 1.186 \mathrm{mGal}$ at TS1, and $\pm 1.441 \mathrm{mGal}$ at TS4 (cf. Featherstone, 1995; Heck, 1990). The indication from Table 4 is that $\delta \phi_{B M}$ propagates into $\gamma$ in Equation (14) and then Equation (13) through $\gamma$, resulting in $\delta \bar{\gamma}$ being approximately equal to $\delta \gamma$. 


\begin{tabular}{lcccc}
\hline $\begin{array}{l}\text { Test } \\
\text { Section }\end{array}$ & $\begin{array}{c}\phi_{1} \\
\text { (south) }\end{array}$ & $\begin{array}{c}\text { AHD } H_{1} \\
(\mathrm{~m})\end{array}$ & $\begin{array}{c}\delta \gamma_{1} \\
(\mathrm{mGals})\end{array}$ & $\begin{array}{c}\delta \bar{\gamma}_{1} \\
(\mathrm{mGals})\end{array}$ \\
\hline TS1 & $26^{\circ} 04^{\prime}$ & 505.686 & 1.186 & 1.187 \\
TS2 & $35^{\circ} 38^{\prime}$ & 1032.153 & 1.427 & 1.427 \\
TS3 & $35^{\circ} 41^{\prime}$ & 1458.857 & 1.427 & 1.427 \\
TS4 & $36^{\circ} 31^{\prime}$ & 1848.747 & 1.441 & 1.441 \\
TS5 & $36^{\circ} 27^{\prime}$ & 2227.960 & 1.440 & 1.440 \\
\hline
\end{tabular}

Table 4. $\bar{\gamma}$ and $\delta \bar{\gamma}$ at BM 1 of each TS, caused by $\delta \phi_{B M}$ of +1 arc-minute.

Assuming maximum $\delta H^{N}$ is $\pm 2 \mathrm{~m}$, and maximum $\phi_{B M}$ is \pm 2 arc-minutes, then maximum $\delta \bar{\gamma}$ caused by $\delta \phi_{B M}$ and $\delta H^{N}$ is $\sim \pm 3 \mathrm{mGal}$. This is much less than the errors identified at some EGM2008 $g_{B M}$ of up to 50 - 60 mGal in Australia (cf. Filmer et al., 2010; Claessens et al., 2009).

$\boldsymbol{N C}$ sensitivity to $\delta \bar{\gamma} . \delta N C$ caused by $\delta \bar{\gamma}$ (third term in Equation (16); using only $\bar{\gamma}_{1}$ ) is proportional to $H_{B M}$, and equivalent to $\delta H O C$ caused by $\delta \bar{g}$ (third term of Equation (4)). However, the maximum $\delta \bar{g}$ could be as large as $\pm 100 \mathrm{mGal}$, while the maximum $\delta \bar{\gamma}$ has been shown above to be $\sim \pm 3 \mathrm{mGal}$. Using Figure 4 (here, $\delta \bar{g}$ is equivalent to $\delta \bar{\gamma} ; \delta H O C$ is equivalent to $\delta N C$ ), when $\delta \bar{\gamma}$ is $\pm 3 \mathrm{mGal}$, the maximum $\delta N C$ is $\sim \pm 10 \mathrm{~mm}$ at TS5. By comparison, $\delta H O C$ is almost $\pm 120 \mathrm{~mm}$ when $\delta \bar{g}$ is $\pm 50 \mathrm{mGal}$, and $\pm 230 \mathrm{~mm}$ when $\delta \bar{g}$ is $\pm 100 \mathrm{mGal}$ at TS5.

$\boldsymbol{N} \boldsymbol{C}$ sensitivity to $\boldsymbol{\delta} \boldsymbol{H}_{\boldsymbol{B M}}$. The effect of $\delta H_{B M}$ on $\delta N C$ (fifth term in Equation (16); using only $H_{1}$ ) is also equivalent to $\delta H O C$ caused by $\delta H_{B M}$ (fifth term of Equation (4)). There may be some small variation due to using $\bar{\gamma}$ instead of $\bar{g}$, but if the maximum $\delta H_{B M}$ are both crudely considered \pm 2 $\mathrm{m}$, the maximum $\delta N C$ caused by $\delta H_{B M}$ will be $\sim \pm 4 \mathrm{~mm}$.

\section{NORMAL-ORTHOMETRIC HEIGHTS}

Normal orthometric heights $H^{N-O}$ are a useful alternative when observed gravity is not available in sufficient quantity or quality (e.g., Rapp, 1961). Here, the Earth’s gravity field is completely replaced 
by the normal gravity field. Thus, with normal potential differences $C^{N}$ replacing $C$ (Filmer et al., 2010; cf. Jekeli, 2000)

$H^{N-O}=\frac{C^{N}}{\bar{\gamma}}$

NOC loop closures remain dependent on the levelling route taken (Heck, 1995, p. 311) and therefore non-holonomic (cf. Sansò and Vaníček, 2006). $H^{N-O}$ are used in numerous vertical datums around the world, e.g., Australia (Roelse et al., 1971); New Zealand (Amos and Featherstone, 2009); the United Kingdom (Ziebart et al., 2008) and Sri Lanka (Abeyratne et al., 2010), among others.

\section{Normal-orthometric height corrections}

$H^{N-O}$ is realised by applying NOCs to $\triangle n$. There are a number of different versions of $N O C$ available; Rapp (1961; $N O C_{R}$ ), Bomford (1980), New Zealand (e.g., Amos and Featherstone, 2009) and Heck (1995). The $N O C_{R}$ is the version that will be investigated here as it is the version used in the AHD (Roelse et al., 1971).

The $N O C_{R}$ formula is (Rapp, 1961, p.16)

$N O C_{R}=\left(A \bar{H}+B \bar{H}^{2}+C \bar{H}^{3}\right) \phi_{1-2}$

where $\bar{H}$ is the average $H^{N-O}$ for $H_{B M}$ at BM1 and BM2 (m), and $\phi_{1-2}$ is the latitude difference (arcminutes) between $\phi_{1}$ and $\phi_{2}$. The coefficients $A, B$ and $C$ in Equation (16) are computed using (Rapp, 1961, p.17)

$$
\begin{aligned}
& A=2 \sin 2 \bar{\phi} \alpha^{\prime}\left(1+\cos 2 \bar{\phi}\left(\alpha^{\prime}-\frac{2 \kappa}{\alpha^{\prime}}\right)-3 \kappa \cos ^{2} 2 \bar{\phi}\right) Q \\
& B=2 \sin 2 \bar{\phi} \alpha^{\prime} t_{2}\left(t_{3}+\frac{t_{4}}{2 \alpha^{\prime}}+\cos 2 \bar{\phi}\left(\frac{3}{2} t_{4}+2 \alpha^{\prime} t_{3}-\frac{2 \kappa t_{3}}{\alpha^{\prime}}\right)\right) Q \\
& C=2 \sin 2 \bar{\phi} \alpha^{\prime} t_{2}^{2} t_{3}\left(t_{3}+\frac{t_{4}}{2 \alpha^{\prime}}+\cos 2 \bar{\phi}\left(2 t_{4}-\frac{2 \kappa t_{3}}{\alpha^{\prime}}\right)\right) Q .
\end{aligned}
$$


where $Q$ is 1 arc-minute in radians and $\bar{\phi}$ is the mid-latitude between $\phi_{B M}$ at BM1 and BM2. The formulas to compute the constants $\alpha^{\prime}, \kappa, t_{2}, t_{3}, t_{4}, d_{3}$ and $c^{\prime}$ are (Rapp, 1961, p.11-14)

$\alpha^{\prime}=\frac{\beta}{2+\beta+2 \epsilon}$

$\kappa=\frac{-2 \epsilon}{2+\beta+2 \epsilon}$

$t_{2}=\frac{2\left(1+f+c^{\prime}\right)}{a\left(1+\frac{\beta}{2}+\epsilon\right)}$

$t_{3}=\frac{1-d_{3}}{2}=1-t_{4}$

$t_{4}=1-t_{3}$

$d_{3}=\frac{\left(3 f-2.5 c^{\prime}\right)}{2}$

$c^{\prime}=\frac{\omega^{2} a^{3}}{G M}$

with $\omega$ the mean angular velocity of the Earth's rotation and $G M$ the product of the Universal gravitational constant and mass of the Earth.

\section{Partial derivatives of the $N O C_{R}$}

As with the $H O C$ (Equation 3), the total differential of the $N O C_{R}$ (Equation 26) is

$\delta N O C_{R}=\frac{\partial N O C_{R}}{\partial A} \delta A+\frac{\partial N O C_{R}}{\partial B} \delta B+\frac{\partial N O C_{R}}{\partial C} \delta C+\frac{\partial N O C_{R}}{\partial \bar{H}} \delta \bar{H}+\frac{\partial N O C_{R}}{\partial \phi_{1-2}} \delta \phi_{1-2}$

with the partial derivatives

$\frac{\partial N O C_{R}}{\partial A}=\bar{H} \phi_{1-2}$

$\frac{\partial N O C_{R}}{\partial B}=\bar{H}^{2} \phi_{1-2}$ 
$\frac{\partial N O C_{R}}{\partial C}=\bar{H}^{3} \phi_{1-2}$

$\frac{\partial N O C_{R}}{\partial \bar{H}}=\left(A+2 B \bar{H}+3 C \bar{H}^{2}\right) \phi_{1-2}$

$\frac{\partial N O C_{R}}{\partial \phi_{1-2}}=A \bar{H}+B \bar{H}+C \bar{H}^{2}$

The $N O C_{R}$ partial derivatives were computed as per the $H O C$ and $N C$

\section{Results for $N O C_{R}$}

$\boldsymbol{N O C _ { \boldsymbol { R } }}$ sensitivity to $\overline{\boldsymbol{\phi}}(\boldsymbol{\delta} \overline{\boldsymbol{\phi}})$. Errors in $\phi_{1}$ and $\phi_{2}$ cause $\delta \bar{\phi}$, which propagate into $\delta N O C_{R}$ through the coefficients $A, B$ and $C$. To test the significance of $\delta \bar{\phi}, A, B$ and $C$ were computed for an assumed value of $\bar{\phi}=35^{\circ} \mathrm{S}$, and then at $\bar{\phi}=35^{\circ} 01^{\prime} \mathrm{S}, \bar{\phi}=35^{\circ} 05^{\prime} \mathrm{S}$ and $\bar{\phi}=35^{\circ} 10^{\prime} \mathrm{S}$ to simulate $\delta \bar{\phi}$ errors of 1, 2 and 10 arc-minutes. Assumed values of $\bar{H}=1000 \mathrm{~m}$ and $\phi_{1-2}=3$ arc-minutes (roughly equivalent to a $5 \mathrm{~km}$ levelling section in the ANLN) were also used. The effect of $\delta \bar{\phi}$ propagating through coefficient $A$ into $\delta N O C_{R}$ is $\pm 0.009 \mathrm{~mm}$ when $\delta \bar{\phi}$ is 10 arc-minutes ( $\left.18 \mathrm{~km}\right) . \delta N O C_{R}$ increases to $\pm 0.018 \mathrm{~mm}$ over $5 \mathrm{~km}$ when the same computation is conducted with $\bar{H}=2000 \mathrm{~m}$. The effect of $B$ and $C$ when $\delta \bar{\phi}$ is 10 arc-minutes (using same assumed values as for $A$ ) on $\delta N O C_{R}$ are < $\pm 0.001 \mathrm{~mm}$. It can be concluded that $N O C_{R}$ is almost completely insensitive to $\delta \bar{\phi}$ propagating through $A, B$ or $C$.

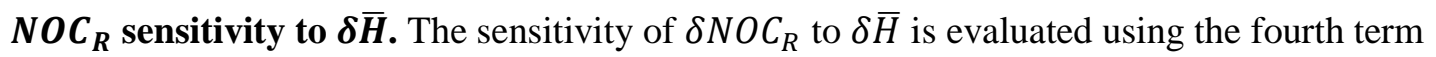
in Equation (37) with assumed values for $\bar{\phi}$ of $35^{\circ} \mathrm{S}, \bar{H}=1000 \mathrm{~m}$ and $\phi_{1-2}=3$ arc-minutes. Figure 6 shows the linear increase in $\delta N O C_{R}$ as $\delta \bar{H}$ increases. The $N O C_{R}$ appears to be rather insensitive to $\delta \bar{H}$; when $\delta \bar{H}$ is $\pm 200 \mathrm{~m}, \delta N O C_{R}$ is $\pm 0.85 \mathrm{~mm}$. Indeed, when $\delta \bar{H}$ is $\pm 10 \mathrm{~m}, \delta N O C_{R}$ is $\pm 0.05 \mathrm{~mm}$, indicating that $\delta N O C_{R}$ is insignificant for maximum $\delta \bar{H}$ of $\pm 2 \mathrm{~m}$. 


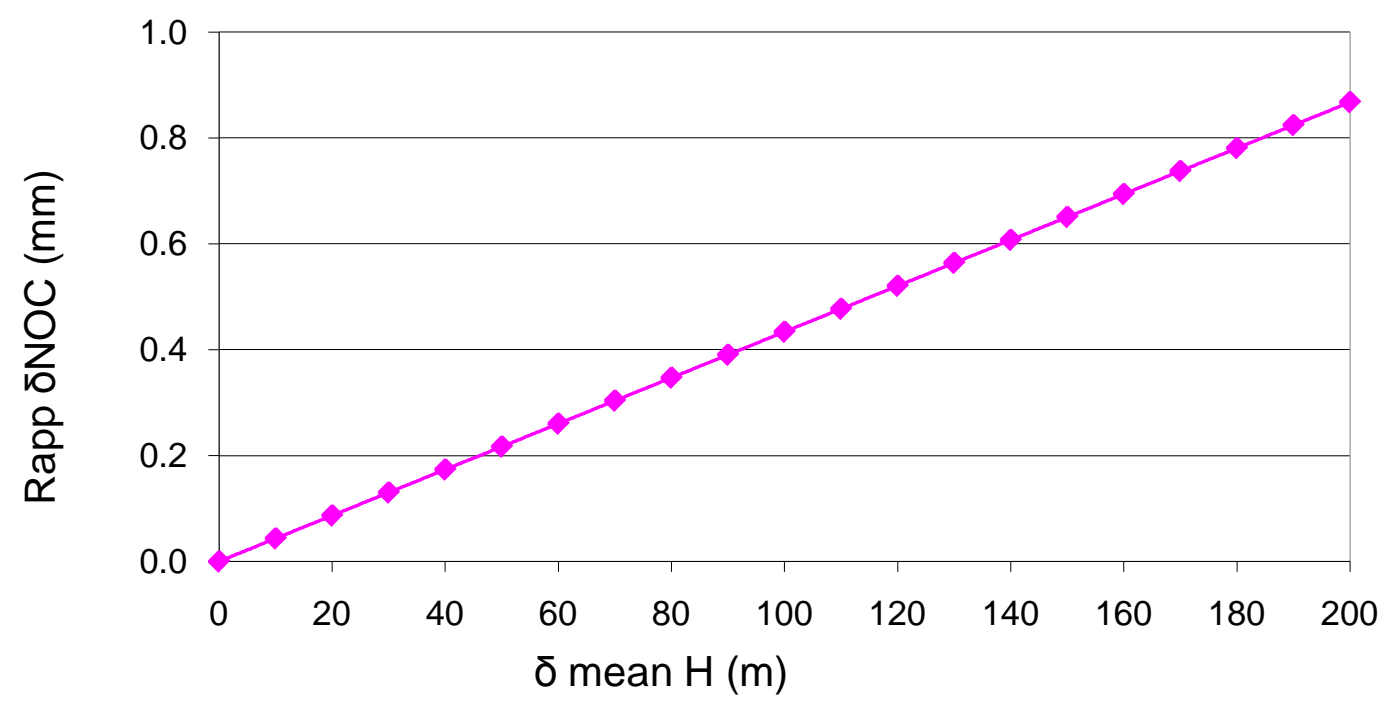

Figure 6. $\delta N O C_{R}$ resulting from $\delta \bar{H}$.

$\boldsymbol{N} \boldsymbol{O O C _ { \boldsymbol { R } }}$ sensitivity to $\delta \phi_{1-2}$. The effect of $\delta \phi_{1-2}$ can be seen in Figure 7. Here, Equation (42) and the fifth term in Equation (37) are evaluated with assumed values of $\bar{H}=1000 \mathrm{~m}$, and $\bar{\phi}=35^{\circ}$. $\delta N O C_{R}$ increases linearly to $\pm 14.5 \mathrm{~mm}$ when $\phi_{1-2}$ is 10 arc-minutes (Figure 7), or $\sim \pm 1.5 \mathrm{~mm}$ per 1 arc-minute of $\delta \phi_{1-2}$. If we consider $\phi_{B M}$ absolute positional uncertainty is \pm 2 arc-minutes, $\delta \phi_{1-2}(\sim$ $\pm 3 \mathrm{~mm}$ ) will tend to cancel out over multiple levelling sub-sections, rather than accumulate. 


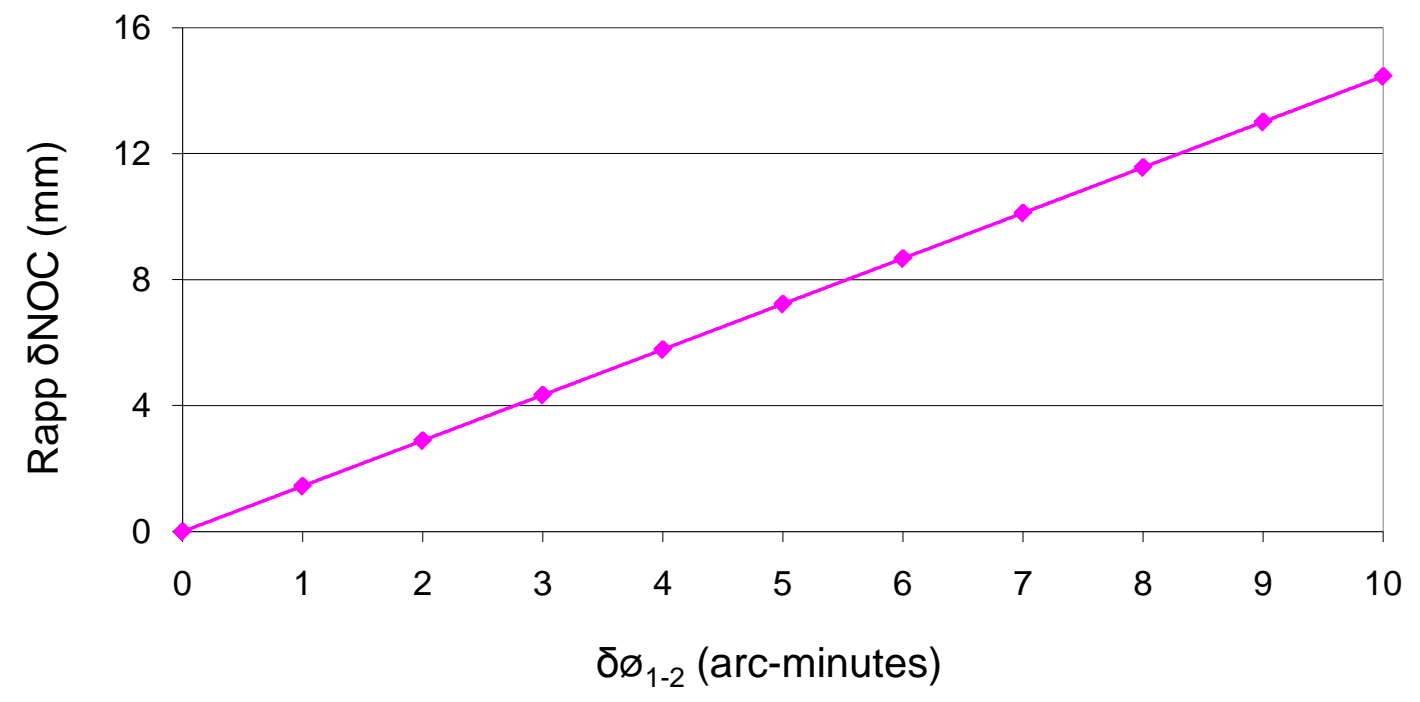

Figure 7. $\delta N O C_{R}$ resulting from $\delta \phi_{1-2}$.

\section{DISCUSSION AND CONCLUSIONS}

HOC. The HOC displays sensitivity to several input values. Of these, it is most sensitive to errors in $\bar{g}$ and has been shown to be directly proportional to $H_{B M}$ (Equations (7) and (8); cf. Heiskanen and Moritz, 1967, p.169). In extreme cases where a gravity error of $\pm 100 \mathrm{mGal}$ occurs at $H_{B M}=\sim 2000 \mathrm{~m}$ (e.g., TS5), the error could reach $\pm 230 \mathrm{~mm}$ (Figure 4). This will contaminate the levelling precision for levelling lines of a few km or less, indicating that it is important to use accurate gravity values at BMs for the HOC.

Equation (5) shows $\delta g$ to be proportional to $\Delta n$, with its effect on the $H O C$, considerably less than for $\bar{g}$. However, it is potentially a significant error depending on the required levelling precision. This is demonstrated at TS4 (Figure 3; $\Delta n \sim 174 \mathrm{~m}$ ), where the simulated error is $\pm 18 \mathrm{~mm}$ if $\delta g$ is $\pm 100 \mathrm{mGal}$. If $\delta g$ is around \pm 10 - $20 \mathrm{mGal}, \delta H O C$ will only be at the mm level, though for high precision levelling, this may become significant as it accumulates.

The maximum magnitude of $\delta H O C$ is $\pm 18 \mathrm{~mm}$ at TS1 when $\delta H_{B M}$ is $\pm 10 \mathrm{~m}$ (Figure 5). It appears to be mostly latitude-dependent. The effect of $\delta \Delta n$ on $\delta H O C$ is also mostly latitude- 
dependent, and reaches $\pm 2 \mathrm{~mm}$ when $\delta \Delta n$ is $\pm 1 \mathrm{~m}$. However, maximum $\delta \Delta n$ will normally be $<30$ mm over a $5 \mathrm{~km}$ levelling line, causing $\delta H O C$ to be $< \pm 1 \mathrm{~mm}$, which is insignificant.

$\boldsymbol{N C}$. The $N C$ also displays sensitivity to the same input values as the $H O C$. It is just as sensitive to $\delta \bar{\gamma}$ as $H O C$ are to $\delta \bar{g}$, but the magnitude of $\delta N C$ (due to $\delta \bar{\gamma}$ ) is much less than $\delta H O C$ (due to $\delta \bar{g}$ ), because maximum $\delta \bar{\gamma}$ is $\sim 3 \mathrm{mGal}$, while $\delta \bar{g}$ can be $\pm 50-60 \mathrm{mGal}$, and potentially up to $\pm 100 \mathrm{mGal}$. However, although $\bar{\gamma}$ can be computed analytically, it is susceptible to $\delta \phi_{B M}$ and $\delta H_{B M}$ in Equation (13) and $\delta \phi_{B M}$ in Equation (14). The effect of $\delta H_{B M}$ on the $N C$ is $\sim 0.1543 \mathrm{mGal}$ per metre of $\delta H_{B M}$, which is roughly half the linear vertical gradient of normal gravity in free air. The effect of $\delta \phi_{B M}$ on $\bar{\gamma}$ in Equation (13) appears to be very small, but it can affect $\bar{\gamma}$ through $\gamma$ in Equation (14) by up to $1.5 \mathrm{mGal}$ (for $\delta \phi_{B M}=1$ arc-minute) when $\phi_{B M}$ is $\sim 43^{\circ} \mathrm{S}$.

$\boldsymbol{N O C _ { \boldsymbol { R } }}$. Errors in Rapp's (1961) coefficients $A, B$ and $C$ resulting from $\delta \bar{\phi}$ appear to have no significant effect on the $N O C_{R}$. The $N O C_{R}$ is somewhat more sensitive to $\delta \phi_{1-2}$ than other $N O C_{R}$ input variables. When $\delta \phi_{1-2}$ is 1 arc-minute, $\delta N O C_{R}$ is $\sim \pm 1.5 \mathrm{~mm}\left(\bar{H}=1000 \mathrm{~m} ; \bar{\phi}=35^{\circ}\right)$, increasing linearly to $\sim \pm 15 \mathrm{~mm}$ when $\delta \phi_{1-2}$ is \pm 10 arc minutes. An error of $1.5 \mathrm{~mm}$ in the $N O C_{R}$, is within the ICSM (2007) class LA tolerance for sections $>\sim 1$ km (cf. Schomaker and Berry, 1981, p. 3-7), suggesting that the effect of $\delta \phi_{1-2}$ on the $N O C_{R}$ is insignificant in most circumstances.

When to apply height corrections? It appears that some errors propagating into the $H O C$ and, to a lesser extent, the $N C$, are significant with respect to the maximum allowable misclosure of different classes of levelling. We can now present some examples of when input errors for computed HCs can cause the HC error to be larger than the maximum allowable misclosure for the levelling section to which it is applied. It is also demonstrated that the HC itself can be larger than the maximum allowable misclosure over a section of levelling. It is important to note that the $N O C_{R}$ is the appropriate $\mathrm{HC}$ for the AHD, and that examples here using the $H O C$ or $N C$ apply only to national vertical datums using these height systems. 
If we consider a typical ANLN levelling section to be $5 \mathrm{~km}$, ICSM (2007) class LC tolerance allows a misclose of up to $26.8 \mathrm{~mm}$ in Australia. An error of more than $\pm 10 \mathrm{mGal}$ in $g_{B M}$ at heights of $\sim 2000 \mathrm{~m}$ (Figure 4) cause HOC errors to exceed the tolerance for class LC levelling. Table 5 can be viewed in conjunction with Figures 3, 4 and 5. The allowable error in $g, \bar{g}$ and $H$ in Figures 3, 4 and 5 can be determined for each levelling section to ensure that the HC error does not exceed the maximum allowable misclose. For example, for HOC errors at TS4 to be within the maximum allowable misclose for ICSM (2007) class LA (4.6 mm), an error in $\bar{g}$ of no more than 1-2 mGal is permissible.

Importantly, the ICSM (2007) misclosure tolerance should not be confused with the estimated precision of the levelling, which will be much lower than the maximum allowable misclose (cf. Kearsley et al., 1993; Morgan, 1992). It should also be remembered that other systematic and random errors will also be present in a levelling line (e.g., Rüeger, 1997; Craymer and Vaníček, 1986; Entin, 1959), so any error propagating through the HC should be much less than the maximum allowable misclose.

\begin{tabular}{lccccccccr}
$\begin{array}{c}\text { Test } \\
\text { Sect. }\end{array}$ & $\begin{array}{c}\text { Dist. } \\
\mathrm{km}\end{array}$ & $\begin{array}{c}\Delta n \\
(\mathrm{~m})\end{array}$ & $\begin{array}{c}H_{A} \\
(\mathrm{~m})\end{array}$ & $\begin{array}{c}H O C \\
(\mathrm{~mm})\end{array}$ & $\begin{array}{c}N C \\
(\mathrm{~mm})\end{array}$ & $\begin{array}{c}N O C_{R} \\
(\mathrm{~mm})\end{array}$ & $\begin{array}{c}\text { LA } \\
(\mathrm{mm})\end{array}$ & $\begin{array}{c}\text { LB } \\
(\mathrm{mm})\end{array}$ & $\begin{array}{c}\text { LC } \\
(\mathrm{mm})\end{array}$ \\
\hline TS1 & 4.80 & 14.8364 & 505.686 & 5.3 & 1.0 & 1.7 & 8.8 & 17.5 & 26.3 \\
TS2 & 0.80 & 15.0821 & 1032.153 & -2.4 & -0.2 & -0.7 & 3.6 & 7.2 & 10.7 \\
TS3 & 0.60 & 60.1965 & 1458.857 & 21.0 & 5.9 & 0.7 & 3.1 & 6.2 & 9.3 \\
TS4 & 1.30 & 174.637 & 1848.747 & 73.0 & 28.1 & 2.1 & 4.6 & 9.1 & 13.7 \\
TS5 & 0.05 & 0.1244 & 2227.960 & 0.1 & 0.0 & 0.1 & 0.9 & 1.8 & 2.7 \\
\hline
\end{tabular}

Table 5. Comparison of $H O C, N C, N O C_{R}$ and ICSM (2007) class LA, LB, and LC maximum allowable misclosure for each test section (cf. Table 1). Note that $N O C_{R}$ assumes north-south levelling lines.

On the other hand, if we assume the HC to be error-free, there are some situations where neglecting to apply the HC can cause above-tolerance errors with respect to the true height difference 
in the relevant height system, in otherwise precise levelling. Table 5 shows all TS with $H O C, N C$ and $N O C_{R}$ (maximum $N O C_{R}$; assumed to be north-south sections so that section length is $\phi_{1-2}$ ) computed for each subsection. The HOC for TS3 exceeds the maximum allowable misclosure for all classes of levelling (the $N C$ exceeds class LC), while both the $H O C$ and $N C$ exceed all maximum allowable misclosures for TS4. The $N O C_{R}$ does not exceed tolerance for any TS, although could be significant at TS4 for ICSM (2007) class LA levelling. However, the $N O C_{R}$ is $9.5 \mathrm{~mm}$ at TS8 over a north-south section of $\sim 5 \mathrm{~km}$, which is slightly above ICSM (2007) class LA tolerance (8.9 mm), but below ICSM class LC tolerance (26.8 mm). The linear dependence of the $N O C_{R}$ on $\phi_{1-2}$ is the largest influence on the magnitude of the $N O C_{R}$.

This information is relevant to surveying practioners when deciding whether it is necessary to apply HCs to small levelling networks or even single levelling sections. When levelling short section lengths in rugged terrain (i.e., large $\Delta n$ ), gravimetric HCs should be applied routinely. However, all HCs accumulate systematically, especially in the north-south direction, as the normal and actual equipotential surfaces converge towards the poles, so that levelling intended for a large levelling network should have HCs applied, however small. For example, $N O C_{R}$ accumulates to almost $0.5 \mathrm{~m}$ from the northern to southern extent of the ANLN (Filmer et al., 2010).

Conclusion. The $H O C$ is the most sensitive to errors in the input values of the three common HCs investigated here. It is particularly sensitive to $\bar{g}$, becoming moreso as height increases. The effect of $\bar{\gamma}$ on the $N C$ is much less than the effect of $\bar{g}$ on $H O C$, because maximum $\delta \bar{\gamma}$ is much smaller than maximum $\delta \bar{g}$. However, it has been shown that $\delta H_{B M}$ and $\delta \phi_{B M}$ do influence $\bar{\gamma}$, which in practical terms cannot then be considered errorless. Both $H O C$ and $N C$ are sensitive to errors in $\delta g$ and $\delta H_{B M}$. $\delta H O C$ and $\delta N C$ due to $\delta g$ are often negligible, but increase when $\delta \Delta n$ is large or in rugged terrain. $\delta H O C$ and $\delta N C$ due to $\delta H_{B M}$ are also often negligible, but are primarily latitudedependent, as they are for $\delta H O C$ and $\delta N C$ caused by $\delta \Delta n$. The $N O C_{R}$ appears insensitive to large 
errors in the input values, provided the length of the levelling section (over which a single $N O C_{R}$ is applied) is limited in the north-south direction (say, $<5 \mathrm{~km}$; i.e., $\phi_{1-2}$ is kept small).

Whether a HC error is considered negligible will often depend on the class of the levelling and length and direction of the levelling section, hence the maximum allowable misclosure. The magnitude of some $H O C$ errors and to a lesser extent $N C$ errors can be larger than the maximum allowable misclosure of the levelling line itself. It was also shown that where the HC is larger than the maximum allowable misclosure, an otherwise precise levelling line will contain an abovetolerance error with respect to the true height difference.

It is recommended that $H O C$ and $N C$ be applied for levelling standards equivalent to ICSM (2007) class LA, LB, and LC, for national vertical datums where these height systems are used. This can become particularly important for heights above $1000 \mathrm{~m}$. It does not appear to be necessary for surveying practitioners to apply the $N O C_{R}$ to levelling standards equivalent to ICSM class LC (ICSM (2007) recommends that it is), though this is dependent on the north-south extent of the levelling. However, the $N O C_{R}$ should be applied to first- and second-order levelling, particularly for heights above $1000 \mathrm{~m}$.

\section{ACKNOWLEDGEMENTS}

This work was partly conducted within the CRC for Spatial Information, established and supported under the Australian Government’s Cooperative Research Centres (CRC) program. Mick Filmer receives financial support from an Australian Postgraduate Award, Curtin’s The Institute for Geoscience Research (TIGeR) and the CRC for Spatial Information. Will Featherstone is the recipient of an Australian Research Council (ARC) Professorial Fellowship (project number DP0663020). The views expressed herein are those of the authors and are not necessarily those of the ARC. We would like to thank Geoscience Australia for supplying the ANLN and gravity datasets. 
We would also like to thank the anonymous reviewers and editor for their comments on this

manuscript. This is The Institute for Geoscience Research (TIGeR) publication number 250.

\section{REFERENCES}

Abeyratne, P.G.V., Featherstone, W.E. and Tantrigoda, D.A. (2010) On the geodetic datums in Sri Lanka. Survey Review, vol. 42, no. 317, pp. 229-239, doi: 10.1179/003962610X12572516251880

Allister, N.A. and Featherstone, W.E. (2001) Estimation of Helmert orthometric heights using digital barcode levelling, observed gravity and topographic mass-density data over part of the Darling Scarp, Western Australia, Geomatics Research Australasia, vol. 75, pp. 25-52.

Amos, M.J., and Featherstone, W.E. (2009) Unification of New Zealand's local vertical datums: iterative gravimetric quasigeoid computations. Journal of Geodesy, vol. 83, no. 1, pp. 57-68, doi: 10.1007/s00190008-0232-y

Bomford, G. (1980) Geodesy, 4th Edn. Oxford University Press, Oxford, UK.

Claessens, S.J., Featherstone, W.E., Anjasmara, I.M. and Filmer, M.S. (2009) Is Australian data really validating EGM2008, or is EGM2008 just in/validating Australian data? Newton's Bulletin, vol. 4, pp. 207251.

Craymer, M. and Vaníček, P. (1986) Further analysis of the 1981 Southern California field test for levelling refraction. Journal of Geophysical Research (Solid Earth and Planets), vol. 91, no. B9, pp. 9045-9055.

Entin, I. (1959) Main systematic errors in precise levelling. Bulletin Géodésique, vol. 33, no. 2, pp. 37-45, doi:10.1007/BF02526861

Featherstone, W.E. and Kuhn, M. (2006) Height systems and vertical datums: a review in the Australian context. Journal of Spatial Science., vol. 51, no. 1, pp. 21-42.

Featherstone, W.E., J.F. Kirby, C. Hirt, M.S. Filmer, S.J. Claessens, N.J. Brown, G. Hu and G.M. Johnston (2010) The AUSGeoid09 model of the Australian Height Datum. Journal of Geodesy (online first) doi: 10.1007/s00190-010-0422-2.

Filmer, M.S. and Featherstone, W.E. (2009) Detecting spirit-levelling errors in the AHD: recent findings and some issues for any new Australian height datum. Australian Journal of Earth Sciences, vol. 56, no. 4, pp. 559-569, doi: 10.1080/08120090902806305.

Filmer, M.S., Featherstone, W.E. and Kuhn, M. (2010) The effect of EGM2008-based normal, normalorthometric and Helmert orthometric height systems on the Australian levelling network, Journal of Geodesy, vol. 84, no. 8, pp. 501-513, doi: 10.1007/s00190-010-0388-0.

Hackney, R.I. and Featherstone, W.E. (2006) Corrigendum to "Geodetic versus geophysical perspectives of the 'gravity anomaly’”. Geophysical Journal International, vol. 167, no. 6, p. 585, doi: 10.1111/j.1365246X.2006.03035.x.

Heck, B. (1995) Rechenverfahren und Auswertemodelle der Landesvermessung, Herbert Wichmann Verlag, Heidelberg, Germany.

Heck, B. (1990) An evaluation of some systematic error sources affecting terrestrial gravity anomalies, Bulletin Géodésique, vol. 64, no. 1, pp. 88-108, doi: 10.1007/BF02530617.

Helmert, F.R. (1890) Die Schwerkraft im Hochgebirge, Insbesondere in den Tyroler Alpen. Veröff. Königl. Preuss. Geod. Inst., No. 1

Heiskanen, W.A. and Moritz, H. (1967) Physical Geodesy, Freeman, San Francisco, USA. 
Hirt, C. and Flury, J. (2008). Astronomical-topographic levelling using high-precision astrogeodetic vertical deflections and digital terrain model data. Journal of Geodesy, vol. 82, no. 4-5, pp. 231-248, doi: 10.1007/s00190-007-0173-x.

Holmes, S.A. and Pavlis, N.K. (2008) A Fortran program for very-high-degree harmonic synthesis. Technical report for harmonic synth version 05/01/2006, National Geospatial Intelligence Agency, Greenbelt, USA.

Holloway, R. (1988) The integration of GPS heights into the Australian Height Datum. UNISURV Report S-33, University of New South Wales, Sydney, Australia.

Hwang C, Hsiao Y-S (2003) Orthometric corrections from levelling, gravity, density and elevation data: a case study in Taiwan. Journal of Geodesy, vol. 77, no. 5-6, pp. 279-291, doi: 10.1007/s00190-003-0325-6

ICSM (2007) Standards and practices for control surveys (SP1), version 1.7, ICSM Publication No. 1, Intergovernmental Committee on Surveying and Mapping, Canberra, http://www.icsm.gov.au/icsm/publications/sp1/sp1v1-7.pdf

Ihde, J. Augath, W. and Sacher, M. (2002) The vertical reference system for Europe. In: Drewes H, Dodson AH, Fortes LPS, Sánchez L, Sandoval P (eds) Vertical Reference Systems, Springer, Berlin Heidelberg New York, pp. 345-350.

Jekeli, C. (2000) Heights, the geopotential and vertical datums. Report No. 459, Ohio State University, Columbus, USA.

Kearsley, A.H.W., Ahmad, Z. and Chan, A. (1993) National height datums, levelling, GPS heights and geoids. Australian Journal of Geodesy, Photogrammetry and Surveying, vol. 59, pp. 53-88.

Lyons, L. (1991) A practical guide to data analysis for physical science students, Cambridge University Press, Cambridge, UK.

Mader, K. (1954) Die orthometrische Schwerekorrektion des Präzisions Nivellements in den Hohen Tauern. Österreichische Zeitschrift für Vermessungswesen, Sonderheft 15, Austria.

Marti, U. and Schlatter, A. (2002) The new height system in Switzerland. In: Drewes H, Dodson AH, Fortes LPS, Sánchez L, Sandoval P (eds) Vertical Reference Systems, Springer, Berlin Heidelberg New York, pp. 50-55.

Meyer, T.H., Roman, D.R. and Zilkoski, D.B. (2006) What does height really mean? Part III: Height Systems, Surveying and Land Information Science, vol. 66, no. 2, pp. 149-160.

Mitchell, H.L. (1973) An Australian geopotential network based on observed gravity. UNISURV Report G18, University of New South Wales, Sydney, Australia, pp. 32-50.

Molodensky, M., Yeremeyev, V. and Yurkina, M. (1962) Methods for study of the external gravitational field and figure of the Earth. Israeli Program for Scientific Translations, Jerusalem, Israel.

Morgan, P. (1992) An analysis of the Australian Height Datum: 1971. The Australian Surveyor, vol. 37, no. 1, pp. 46-63.

Moritz, H. (1980) Geodetic reference system 1980. Bulletin Géodésique, vol. 54, no. 3, pp. 395-405, doi: 10.1007/BF02521480.

Murray, A. (1997) The Australian national gravity database, AGSO Journal of Australian Geology \& Geophysics, vol, 17, no. 1, pp. 145-155.

Niethammer, T. (1932) Nivellement und Schwere als Mittel zur Berechnung wahrer Meereshöhen. Schweizerische Geodätische Kommission, Switzerland.

Papp, G., Szeghy, E.and Benedek, J. (2009). The determination of potential difference by the joint application of measured and synthetical gravity data: a case study in Hungary. Journal of Geodesy, vol. 83, no. 6, pp. 509521, doi: 10.1007/s00190-008-0257-2.

Pavlis, N.K., Holmes, S.A., Kenyon, S.C. and Factor, J.K. (2008) An Earth gravitational model to degree 2160: EGM2008. Presented at EGU-2008, Vienna, Austria, April 13-18.

Rapp, R.H. (1961) The orthometric height. MSc Dissertation, Ohio State University, Columbus, USA.

Roelse, A., Granger, H.W. and Graham, J.W. (1971) The adjustment of the Australian levelling survey 19701971. Technical Report 12, Division of National Mapping, Canberra, Australia. 
Rüeger, J.M. (1997) Staff errors in and the adjustment of ordinary levelling runs. The Australian Surveyor, vol. 42, no. 1, pp. 16-24.

Sansò, F. and Vaníček, P. (2006) The orthometric height and the holonomity problem. Journal of Geodesy, vol. 80, no. 5, pp. 225-232, doi: 10.1007/s00190-005-0015-7.

Schomaker, M.C. and Berry, R.M. (1981) Geodetic Leveling. National Geodetic Survey, NOAA Manual NOS NGS 3, Rockville, USA. Reprinted June 2001, http://www.ngs.noaa.gov/PUBS_LIB/Geodeticleveling_nos_3.pdf

Strang van Hees, G.L. (1992) Practical formulas for the computation of the orthometric, dynamic and normal heights. Zeitschrift fur Vermessungswesen, vol. 117, no. 11, pp. 727-734.

Strange, W. (1982) The evaluation of orthometric height accuracy using bore hole gravimetry, Bulletin Géodésique, vol. 56, no. 4, pp. 300-311, doi: 10.1007/BF02525730.

Tenzer, R., Vaníček, P., Santos, M., Featherstone, W.E. and Kuhn, M. (2005) Rigorous determination of the orthometric height. Journal of Geodesy, vol. 79, no.1-3, pp. 82-92, doi 10.1007/s00190-005-0445-2.

Torge W (2001) Geodesy, 3rd. Edn. De Gruyter, Berlin New York.

Vaníček, P. and Krakiwsky, E. (1982) Geodesy: The concepts, North-Holland, Amsterdam New York Oxford.

Vaníček, P. Castle, R.O. and Balazs, E.I. (1980) Geodetic levelling and its applications. Reviews of Geophysics and Space Physics, vol. 18, no. 2, pp. 505-524, doi: 10.1029/RG018i002p00505.

Ziebart, M.K., Illife, J.C., Forsberg, R. and Strykowski, G. (2008) Convergence of the UK OSGM05 GRACEbased geoid and the UK fundamental benchmark network, Journal of Geophysical Research, vol. 113, article B12401, doi: 10.1029/2007JB004959.

Zilkoski, D.B., Richards, J.H. and Young, G.M. (1992) Results of the general adjustment of the North American Vertical Datum of 1988. Surveying and Land Information Systems, vol. 52, pp. 133-149. 